九州大学学術情報リポジトリ

Kyushu University Institutional Repository

\title{
Analysis of the Gut Contents of the Internal Exotic Fish Species Opsariichthys uncirostris uncirostris in the Futatsugawa River, Kyushu Island, Japan
}

Kurita, Yoshihisa

Faculty of Life and Environmental Science, Tsukuba University

Nakajima, Jun

Faculty of Engineering, Kyushu University

Kaneto, Jun

Laboratory of Aquatic Field Science, Division of Aquatic Field Science, Department of Animal and Marine Biosource Science, Faculty of Agriculture, Kyushu University

Onikura, Norio

Laboratory of Aquatic Field Science, Division of Aquatic Field Science, Department of Animal and Marine Biosource Science, Faculty of Agriculture, Kyushu University

https://doi.org/10.5109/12853

出版情報: 九州大学大学院農学研究院紀要. 53 (2)，pp.429-433，2008-10-28. Faculty of Agriculture, Kyushu University

バージョン:

権利関係 : 


\title{
Analysis of the Gut Contents of the Internal Exotic Fish Species Opsariichthys uncirostris uncirostris in the Futatsugawa River, Kyushu Island, Japan
}

\author{
Yoshihisa KURITA ${ }^{1}$, Jun NAKAJIMA ${ }^{2}$, Jun KANETO ${ }^{3}$ \\ and Norio ONIKURA ${ }^{3 *}$
}

\author{
Laboratory of Aquatic Field Science, Division of Aquatic Field Science, Department of Animal \\ and Marine Biosource Science, Faculty of Agriculture, Kyushu University, \\ Fukuoka 811-3304, Japan \\ (Received June 27, 2008 and accepted July 16, 2008)
}

\begin{abstract}
Opsariichthys uncirostris uncirostris was introduced from Lake Biwa to several freshwater areas in Kyusyu Island, and the gut contents of this fish were observed in order to evaluate the effect of internal invasion on native aquatic organisms. The fish specimens were captured in the Futatsugawa river, northwestern Kyushu Island, Japan, between February 2007 and January 2008, and their gut contents were examined under a stereomicroscope. The gut contents of this exotic species comprised various prey animals, mainly fishes in most of the seasons. The empty gut ratio was approximately $80 \%$ in several seasons and 100\% during February and March. This exotic species showed high selectivity for Zacco spp., Pseudorasbora parva, Tanakia spp., and Rhodeus spp., which had large populations at the study sites. In contrast, this exotic species showed no selectivity for Carassius spp. that also had a large population. Acheilognathus spp. that had a small population at this study site showed high selectivity as prey by this exotic species. A. tabira nakamurae, a native species, is listed as threatened in the Japanese Red Data Book. Native species with a small population and high prey selectivity were estimated to be the most negatively effected species by the internal invasion of the study site by this exotic species.
\end{abstract}

\section{INTRODUCTION}

The effect of the invasion of nonnative fishes on native fishes is a serious problem worldwide. Exotic species are introduced into different environments for aquaculture (Casal, 2006), eliminating mosquito larva (Hirose et al., 1997; Tashiro et al., 2007), game fishing (Hosoya, 2005), or from ships' ballast water (Sapota and Skora, 2005). These invaders have undesirable effects on native fish species: the population of the native species decreases because they are driven to seek alternative habitats, and their hatching success is reduced due to predation, depletion of food resources, or other pressures resulting from the invader's presence (Azuma, 1992; Yodo and Kimura, 1998; Maezono and Miyashita, 2003; Townsend, 2003; Corkum et al., 2004; Katano et al., 2005; Madeira et al., 2005). In Japan, most studies have evaluated the effects of invasions by exotic fishes such as Micropterus salmoides, Lepomis macrochirus, and Gambusia affinis (Yodo and Kimura, 1998; Maezono and Miyashita, 2003; Tashiro et al., 2007) on native fish species and have recommended methods for the extermination of the nonnative fishes (Katano et al., 2005). Today, the rearing, movement, and release of nonnative fishes in the environments of native fishes are regulated by legislation.

1 Faculty of Life and Environmental Science, Tsukuba University, 1-1-1 Tennodai, Tsukuba, Ibaraki 305-8572, Japan

Faculty of Engineering, Kyushu University, 744 Motooka, Fukuoka 819-0395, Japan

Laboratory of Aquatic Field Science, Division of Aquatic Field Science, Department of Animal and Marine Biosource Science, Faculty of Agriculture, Kyushu University, Fukuoka 811-3304, Japan

* Corresponding author (E-mail: onikura@agr.kyushu-u.ac.jp)
Japan is facing other challenges due to such invasions. Exotic fishes have been introduced into different environments from internal regions for aquaculture and game fishing; these fishes commingle with the juveniles of the ayu Plecoglossus altivelis altivelis, which have been released into rivers (Katano and Mori, 2005). However, invasions by fishes from internal regions have not been as well investigated as those by fishes from foreign countries. Evaluation of the effects of internal invasion on native species is also an urgent need.

Opsariichthys uncirostris uncirostris introduced from Lake Biwa is known to distribute in the creeks around Ariake Bay in northwestern Kyushu Island, Japan (Onikura et al., 2008). In Lake Biwa, this species feeds on small fishes such as $P$. altivelis altivelis, bitterlings, and gobies (Tanaka, 1964). This exotic species needs to be investigated in detail as a species that poses an environmental threat. We investigated the gut contents of this exotic species, which has been introduced from Lake Biwa, in order to evaluate the effect of internal invasion on native aquatic organisms.

\section{MATERIALS AND METHODS}

\section{Specimen collection}

O. uncirostris uncirostris individuals were collected from the Futatsugawa river $\left(32^{\circ} 10^{\prime} \mathrm{N}, 130^{\circ} 26^{\prime} \mathrm{E}\right)$ and an irrigation ditch around this river in northwestern Kyushu Island, Japan. Samplings were conducted every month or twice a month form February 2006 to January 2007. The individuals were sampled 50 times using casting nets (mesh size: approximately $12 \mathrm{~mm}$ ).

\section{Observation}

The individuals that were collected were used as 
specimens. In total, 490 (70-249 mm in body length) specimens were collected. These specimens were fixed in 10\% buffered formalin, their guts were removed, and the gut contents were observed under a Nikon stereomicroscope.

\section{Empty gut ratio and food selective index}

Chiou et al. (2005) calculated the empty stomach ratio in order to analyze the feeding activities of Taiwan mauxia shrimp. Since $O$. uncirostris uncirostris has no stomach, we estimated the seasonal changes in its feeding activities by calculating the empty gut ratio (EGR). The EGR was calculated by using the following equation:

$$
\begin{aligned}
& E G R=100 \times N_{\text {empty }} / N_{\text {total }} \\
& N_{\text {empty }}: \text { number of individuals with an empty gut } \\
& N_{\text {total }} \text { : total number of specimens }
\end{aligned}
$$

Prey selectivity was also investigated in the context of seasonal changes by calculating the food selective index $\left(E_{i}\right)$ of Yoshihara and Fukuda (1998). The number of individuals of each species captured as bycatch in 50 casts was counted, and this number was used as the stock biomass for each species at the sampling site $\left(p_{i}\right)$. We also used the number as the population of each species at the site. In addition, the number of individuals of each species observed in the guts of the exotic species was counted and considered as the predation intake $\left(r_{i}\right)$. The $E_{i}$ was calculated using the following equation:

$$
E_{i}=\left(r_{i}-p_{i}\right) /\left(r_{i}+p_{i}\right)
$$

The $E_{i}$ values are positive when the gut contents contain prey preferred by this exotic species, and they are negative when the prey preferred by this species decreases in the gut.

The $E_{i}$ values and fish population data were established for each prey fish species every 2 months in order

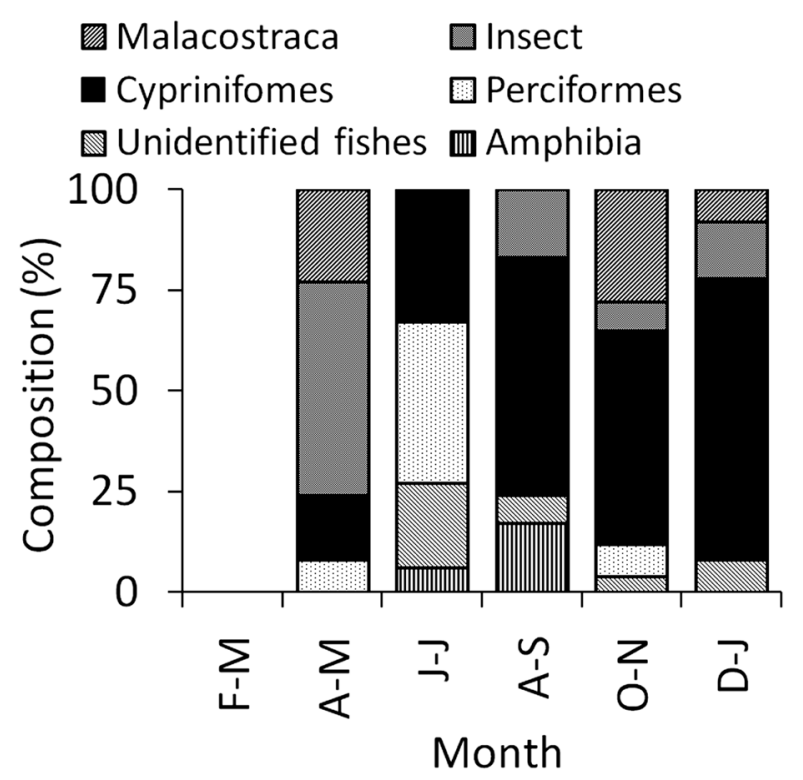

Fig. 1. Seasonal changes in the composition of the gut contents of O. uncirostris uncirostris captured from the Futatsugawa river, Kyushu Island, Japan. to evaluate the impact of this exotic species on the native species. Log transformations were conducted on the fish population data, and a cluster analysis was performed by the Ward method by using these data.

\section{RESULTS AND DISCUSSION}

\section{Food composition}

Figure 1 shows the seasonal variation in prey-animal composition in the gut contents of $O$. uncirostris uncirostris. During April and May, the gut contents mainly comprised insects (38.5\%) and Malacostraca (23.1\%). This exotic species fed mainly on fishes (96.3\%) during June and July, and the Rhinogobius sp. OR constituted $40.7 \%$ in the gut contents. During August and September, the fish species were mainly observed, and 58.3\% of the gut contents comprised Cyprinidae individuals. Cyprinidae individuals were also preyed on between October and January. However, during February and March, all individuals of this exotic species had empty guts.

The analysis of the gut contents of $O$. uncirostris uncirostris revealed various prey animals, mainly fishes, in almost all seasons. Among the prey fishes, Rhinogobius spp. were the main prey in summer, while Cyprinidae individuals were the chief prey after summer. These characteristics of the feeding habit of O. uncirostris uncirostris corresponded with that of the native inhabitants of Lake Biwa (Tanaka, 1964). However, in the study sites in the Futatsugawa river, this species showed no feeding during winter. However, in Lake Biwa the juveniles and young fish of $P$. altivelis altivelis are often preyed on by this exotic species in winter (Tanaka, 1964). Although individuals of $P$. altivelis altivelis inhabiting Lake Biwa survive winter, those inhabiting the rivers in Kyushu Island survive winter by migration to coastal regions (Nishda, 2005). The ecological differences between $P$. altivelis altivelis from the 2 areas might be related to the difference in the feeding habits of $O$. uncirostris uncirostris between these 2 areas.

\section{Seasonal changes of empty gut rate and food selec- tivity}

Figure 2 shows the seasonal changes in the $E G R$ of $O$. uncirostris uncirostris captured from the Futatsugawa river, as determined in this study, and the $E G R$ of the individuals inhabiting Lake Biwa, as reported by Tanaka (1964). In the Futatsugawa river, the $E G R$ was calculated as approximately 80\% between April and January, and the values were 100\% during February and March. In Lake Biwa, the values were less than $40 \%$ all year long; this was significantly lower than those in the Futatsugawa river (Mann-Whitney $U$ test; $p<0.01$ ). The $E G R$ in the Futatsugawa river may be higher than those in Lake Biwa due to insufficient prey in the Futatsugawa river, which is a transmigration area of $O$. uncirostris uncirostris.

Figure 3 shows the $E_{i}$ of $O$. uncirostris uncirostris and the population (stock biomass) of each prey animal. 


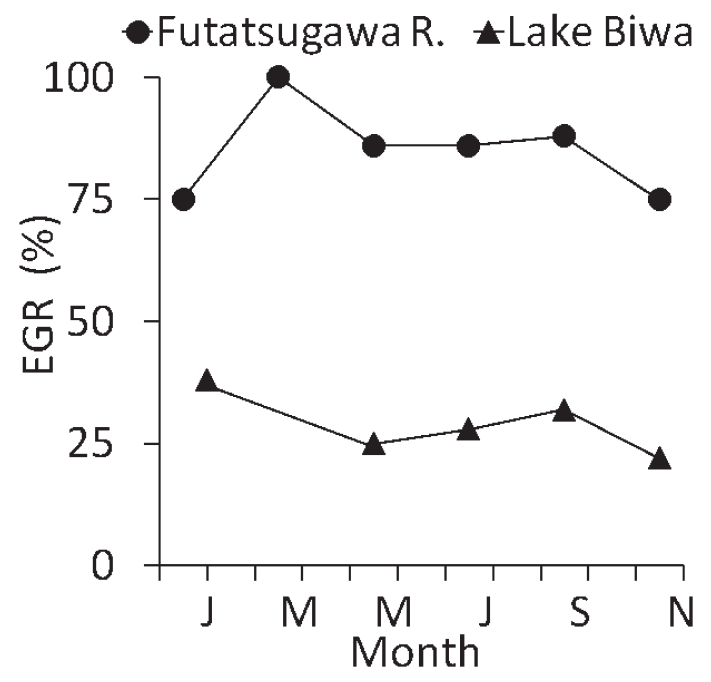

Fig. 2. Seasonal changes in the empty gut ratio $(E G R, \%)$ of $O$. uncirostris uncirostris captured from the Futatsugawa river, Kyushu Island, Japan and the EGR of the individuals inhabiting Lake Biwa, as reported previously by Tanaka (1964).
There were large populations of Zacco spp., Carassius spp., Pseudorasbora parva, Tanakia spp., and Rhodeus spp. at our study site. The $E_{i}$ values of this exotic species were positive between August and January for Zacco spp.; during June and July, for P. parva; during April and May, for Tanakia spp.; and during August and September, for Rhodeus spp. In contrast, the $E_{i}$ for Carassius spp., which had a large population, was negative, suggesting that this exotic species does not prefer this native fish as prey. In case of native fishes with small populations, the $E_{i}$ was positive during October and November for Abbottina rivularis and Biwia zezera; during December and January, for Acheilognathus spp.; from June to July and from December to January, for Rhinogobius sp. OR; and during April and May, for Odontobutis obscura. These native fishes with small populations were estimated to be preyed on selectively by this exotic species.

Cluster analysis was performed using the $E_{i}$ values and fish population data, and the prey fishes were classi-

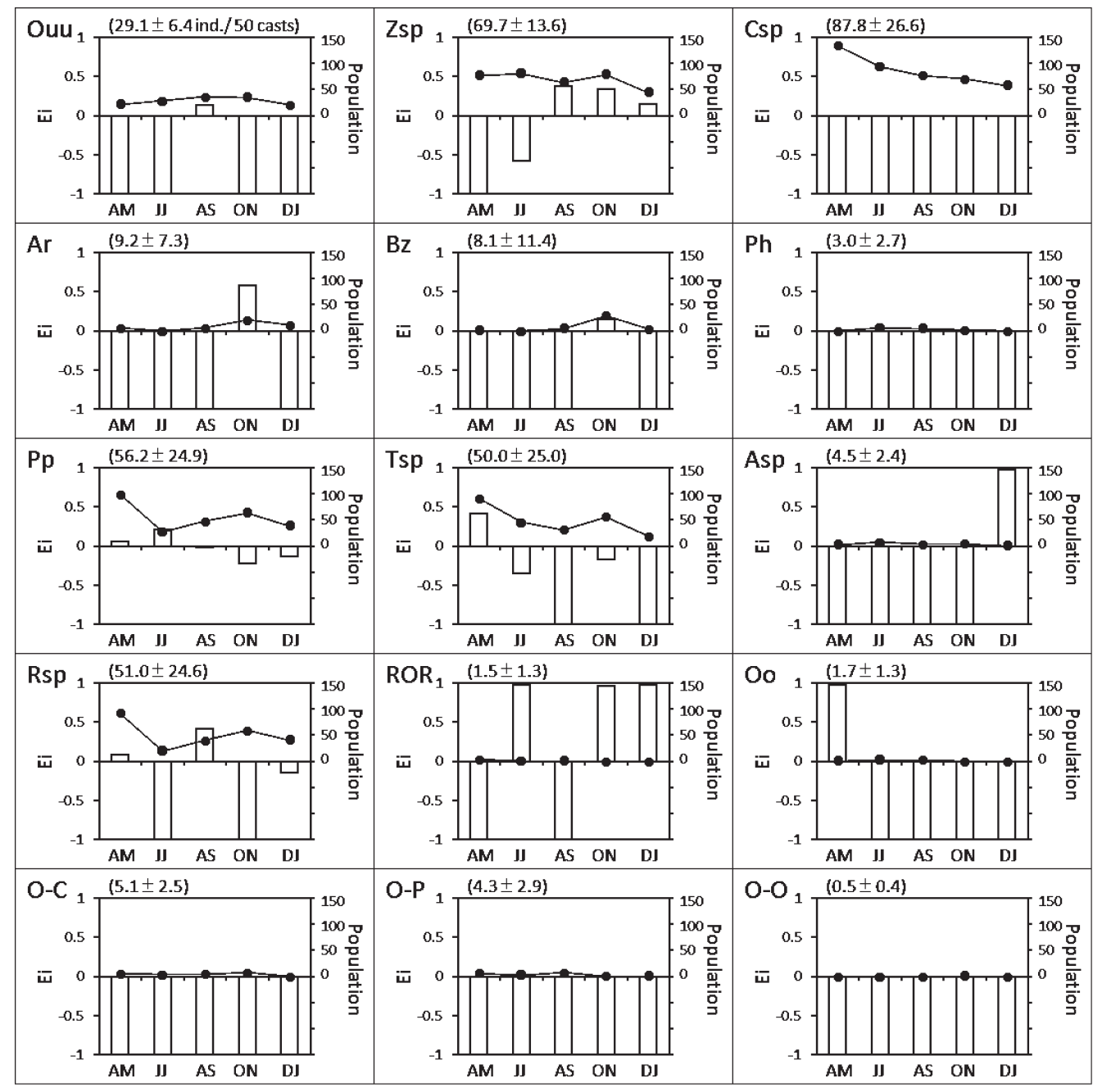

Fig. 3. Food selective index $\left(E_{i}\right)$ of $O$. uncirostris uncirostris for the population of each prey species in the Futatsugawa river, Kyushu Island, Japan. The dots, bars, and parentheses indicate the $E_{i}$ values, populations, and the averages of the populations, respectively. The acronyms used for a prey animal species or genus are as follows: Ouu, O. uncirostris uncirostris; Zsp, Zacco spp.; Csp, Carassius spp.; Ar, Abbottina rivularis; Bz, Biwia zezera; Ph, Pungtungia herzi; Pp, Pseudorasbora parva; Tsp, Tanakia spp.; Asp, Acheilognathus spp.; Rsp, Rhodeus spp.; ROR, Rhinogobius sp. OR; Oo, Odontobutis obscura; O-C, other Cypriniformes; O-P, other Perciformes; O-O, other fishes. 
fied into 6 groups: no population and no selectivity (Group 1), low population and no selectivity (Group 2), low population and high selectivity (Group 3), moderate population and no selectivity (Group 4), high population and moderate selectivity (Group 5), and high population and no selectivity (Group 6) (Fig. 4). This classification suggested that this exotic species had the largest impact in each season on the native species in Group 3. $O$. obscura, Acheilognathus spp., and Rhinogobius sp. OR were estimated to be at high risk from April to May; December to January; and June to July, and from October to January, respectively.

\section{Predation of threatened fish species}

Among the native species that were present in the gut of this exotic species, Rhodeus ocellatus kurumeus (Fig. 5), Tanakia limbata, and T. lanceolata are ranked as threatened species in the Japanese Red Data Book (Ministry of Environment, 2003). Although the $E_{i}$ values for these native species were positive in several

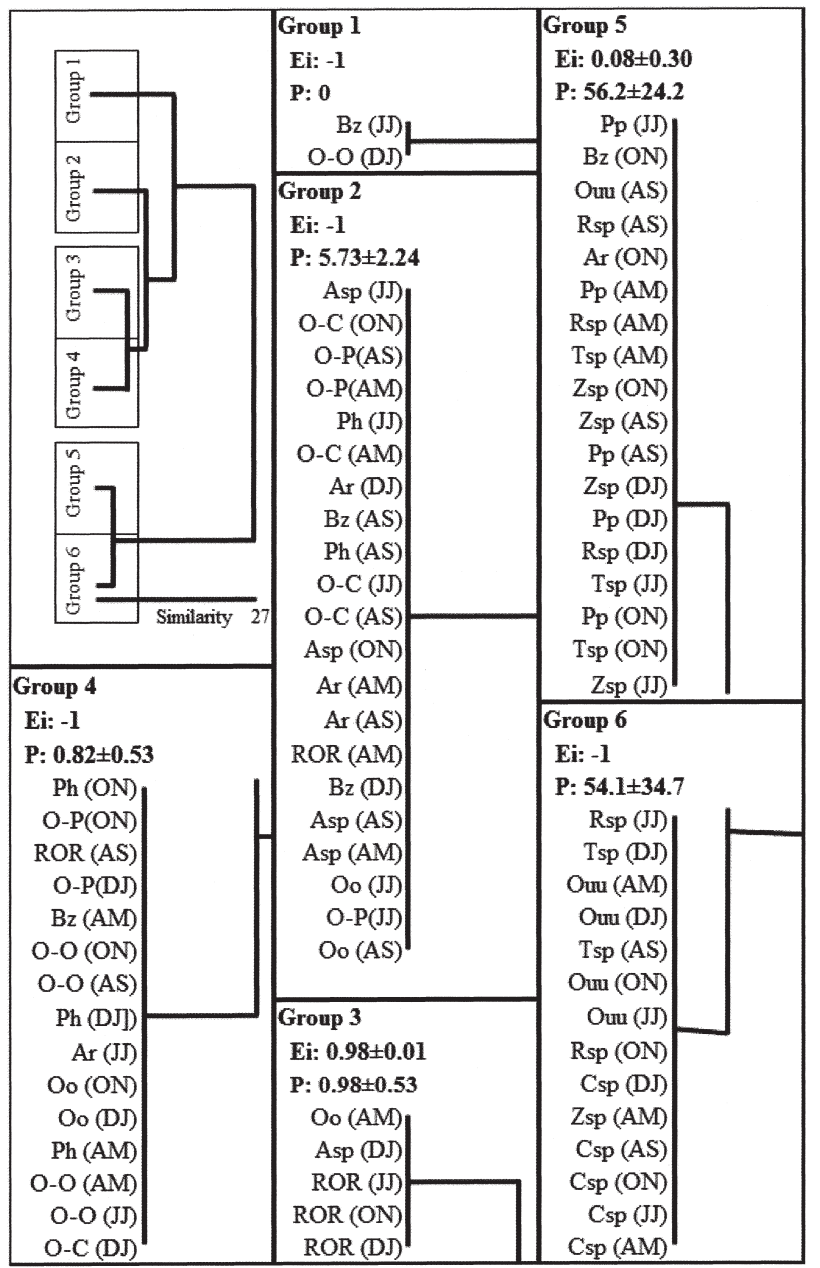

Fig. 4. Similarity in the relationship between the population and the prey selectivity in each prey fish in each season. The acronyms used for a prey animal species or genus are the same as those used in Figure 3. The parentheses indicate the following seasons: AM, April to May; JJ, June to July; AS, August to September; ON, October to November; DJ, December to January. In each group, the average values of $E_{i}$ and population are indicated in this figure.

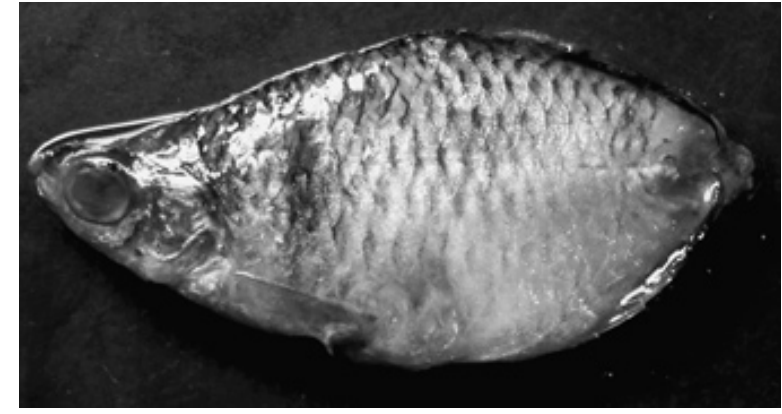

Fig. 5. Rhodeus ocellatus kurumeus found in the gut of $O$ uncirostris uncirostris captured in the Futatsugawa river, Kyushu Island, Japan.

seasons, their average population was more than 50 individuals/50 casts (Fig. 3), suggesting that these threatened native species were not largely effected by the feeding behavior of $O$. uncirostris uncirostris. The $E_{i}$ for $A$. rivularis, another endangered native species, was also positive from October to November (Fig. 3). Although the average annual of the population in this species was small (approximately 9.2), it increased from October to January. Therefore, this native species was estimated to be preyed upon by $O$. uncirostris uncirostris when its population size was large but not when its population size was small. Therefore, by performing the cluster analysis (Fig. 4), we classified this native species into Group 5 (high population and moderate selectivity) from October to November, and this result was confirmed in this study.

In this field sampling, 28 individuals of Acheilognathus tabira nakamurae, which are classified as Acheilognathus spp., were present in the gut contents; this species is also a threatened native species (Ministry of Environment, 2003). The population of Acheilognathus spp. indicates one-seventh of the population of the exotic species (Acheilognathus spp./ O. uncirostris uncirostris, 4.5/29.1) and had positive $E_{i}$ values in winter (Fig. 3). By using cluster analysis, individuals belonging to this genus were classified into Group 3 (low population and high selectivity) (Fig. 4). These results suggest that A. tabira nakamurae is probably the most negatively effected species due to internal invasion of the study site by the exotic species O. uncirostris uncirostris.

Further ecological research involving parameters such as age, growth, and reproduction of this exotic species is needed in order to control internal invasion by this species. In addition, for some time in the future, we must monitor the changes in the populations of both the exotic and native threatened species at sites where both species are sympatric.

\section{ACKNOWLEDGEMENTS}

This study was in part supported by the Global Environment Research Fund (RF-075) of the Ministry of the Environment, Japan. 


\section{REFERENCES}

Azuma, M. 1992 Ecological release in feeding behaviour; the case of bluegills in Japan. Hydrobiologia 243/244: 269-276

Casal, C. M. V. 2006 Global documentation of fish introductions: the growing crisis and recommendations for action. Biol. Invas. 8: $3-11$

Corkum, L. D., M. R. Sapota and K. E. Skora 2004 The round goby, Neogobius melanostomus, a fish invader on both sides of the Atlantic Ocean. Biol. Invas. 6: 173-181

Chiou, W. D., J. J. Hwang, L. Z. Cheng and C. T. Chen 2005 Food and feeding habit of Taiwan mauxia shrimp Acetes intermedius in the coastal water of southwestern Taiwan. Fish. Sci. 71: 361-366

Hirose, Y., S. Okubo and H. Sato 1977 The spread of Gambusia affinis distributed from Tokushima city to the western part of Japan. Jap. J. Sanit. Zool. 28: 337-338

Hosoya, K. 2005 Micropterus dolomieu. In "Freshwater fishes of Japan", ed. by H. Kawanabe, N. Mizuno and K. Hosoya, YAMA-KEI Publisher, Tokyo, pp. 504

Katano, O. and S. Mori 2005 Kisho-Gyorui no Genzai to Mirai, Shinzansha, Tokyo (Japan)

Katano, O., T. Nakamura and S. Yamamoto 2005 Prey fish selection by Far Eastern catfish Silurus asotus and largemouth bass Micropterus salmoides. Fish. Sci. 71: 862-868

Madeira, M. J., B. J. Gomez-Moliner and A. M. Barbe 2005 Genetic introgression on freshwater fish populations caused by restocking programmes. Biol. Invas. 7: 117-125

Maezono, Y. and T. Miyashita 2003 Community-level impacts induced by introduced largemouth bass and bluegill in farm ponds in Japan. Biol. Conserv. 109: 111-121
Ministry of the Environment 2003 Threatened Wildlife of Japan-Red Data Book 2nd ed.-Vol.4, Pisces-Brackish and Fresh Water Fishes, Japan Wildlife Research Center, Tokyo (Japan)

Nishida, M. 2005 Plecoglossus altivelis altivelis. In "Freshwater fishes of Japan", ed. by H. Kawanabe, N. Mizuno and K. Hosoya, YAMA-KEI Publisher, Tokyo, pp. 66-79

Onikura, N., J. Nakajima, K. Eguchi, T. Miyake, K. Kawamura and Y. Kurita 2008 Present distributions of exotic species in creeks around Sea of Ariake and Yatsushiro, northwestern Kyushu, Japan. Journal of Japan Society on Water Environment 31(7): in press

Sapota, M. R. and K. E. Skora 2005 Spread of alien (non-indigenous) fish species Neogobius melanostomus in the Gulf of Gdansk (south Baltic). Biol. Invas. 7: 157-164

Tanaka, S. 1964 The food and growth of "hasu", Opsariichthys uncirostris (T.\&S.) in the Lake Biwa. Phys. Ecol. Jpn. 12 106-114

Tashiro, Y., Y. Sato and Y. Kozuki 2007 Intentional release records for 37 years of the alien mosquitofish, Gambusia affinis (Cyprinodontiformes: Poeciliidae), in Tokushima City, Japan. Bulletin of the Tokushima Prefecture Museum 17: 123-138

Townsend, C. R. 2003 Individuals, population, community, and ecosystem consequences of a fish invader in New Zealand streams. Conserv. Biol. 17: 38-47

Yodo, T. and S. Kimura 1998 Feeding habits of largemouth bass Micropterus salmoides in Lakes Shorenji and Nishinoko, central Japan. Nippon Suisan Gakkaishi 64: 26-38

Yoshihara, K. and T. Fukuda 1998 Food selectivity of the jack mackerel kept in a cage equipped with an underwater lamp. SUISANZOSHOKU 46: 591-592 